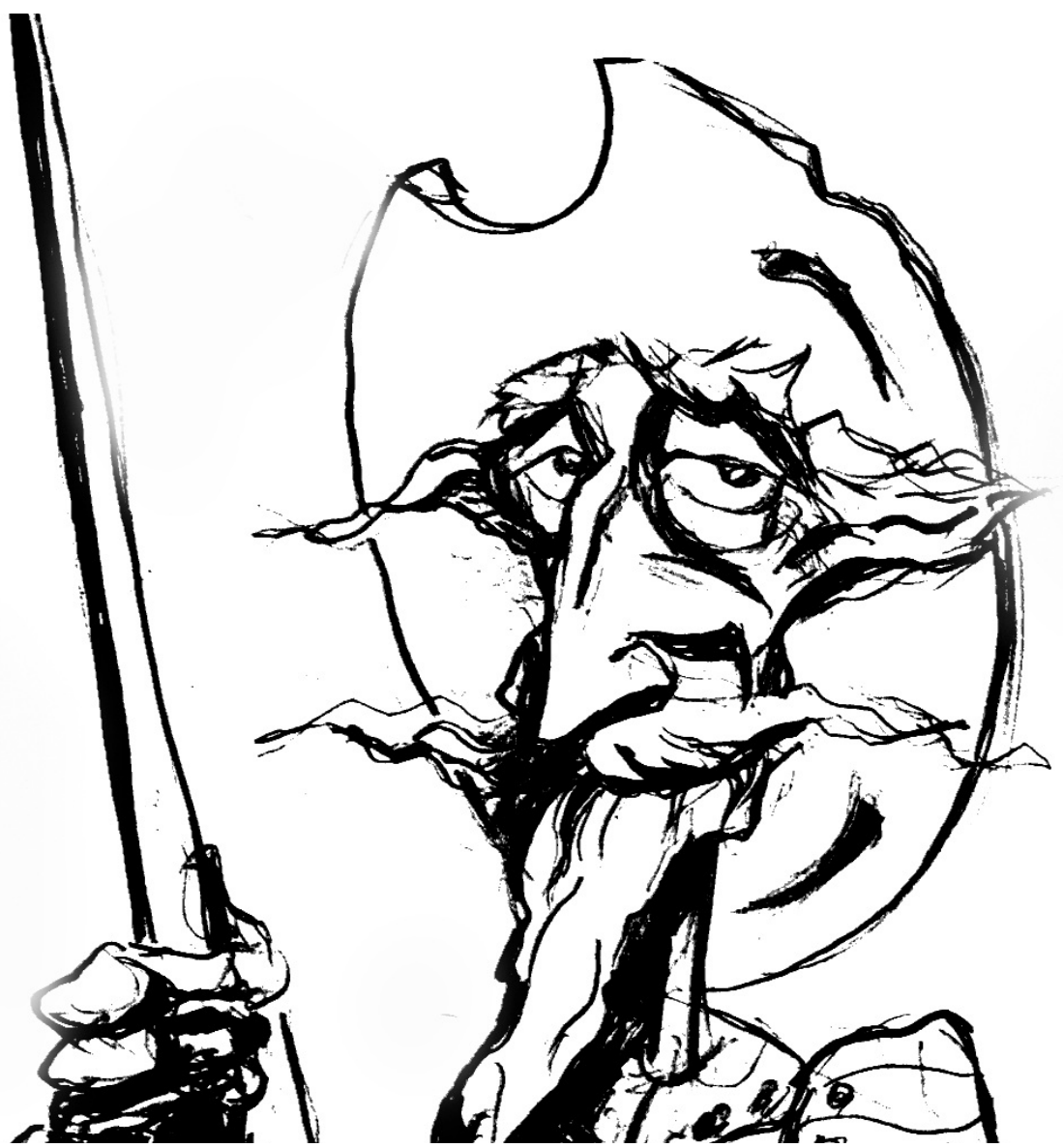

Estrategias para traducir la alteridad: los nativos rioplatenses entre sus testigos directos y la Historia general de los hechos de los castellanos de Antonio de Herrera y Tordesillas (1536-1615)

[María Juliana Gandini] 



\section{Estrategias para traducir la alteridad: los nativos rioplatenses entre sus testigos directos y la Historia general de los hechos de los castellanos de Antonio de Herrera y Tordesillas (1536-1615)

\author{
Strategies for Translating Otherness: The Native Peoples of the Rio de La \\ Plata between their Direct Witnesses and Historia general de los hechos de los \\ castellanos (1536-1615) by Antonio de Herrera y Tordesillas
}

MARÍA JULIANA GANDINI

Resumen

Este trabajo propone analizar la producción de representaciones sobre los nativos del Río de la Plata en dos instancias diferenciales. Primero, durante su primera conquista (1536-1545) considerando textos generados por sus testigos directos, agentes coloniales españoles instalados en un territorio ajeno; luego, la reapropiación de estas representaciones en el proyecto historiográfico de Antonio de Herrera y Tordesillas (1601-1615). Tomando a ambas como casos de traducción cultural, pretendemos iluminar las operaciones intelectuales que fue necesario realizar para comprender y comunicar la forma de vida de las sociedades nativas americanas en dos contextos diferentes pero próximos en el tiempo.

Palabras Clave

Conquista del Río de la Plata; Historiografía; Recepción cultural; Testimonio Directo; Traducción cultural

\begin{abstract}
This paper aims to analyze the production of representations about the native peoples of the Rio de La Plata in two different instances. The first, during its first conquest (1536-1545), considers texts produced by their direct witnesses, Spanish colonial agents installed in an foreign territory; then, the reappropriation of these representations in the historiographical project of Antonio de Herrera y Tordesillas (1601-1615). Taking both of them as cases of cultural translation, we intend to stress the intellectual operations needed to understand and communicate American native peoples' ways of life in two different contexts that were nevertheless close in time.
\end{abstract}

Keywords

Conquest of La Plata River; Cultural Reception; Cultural Translation; First Hand Testimony; Historiography

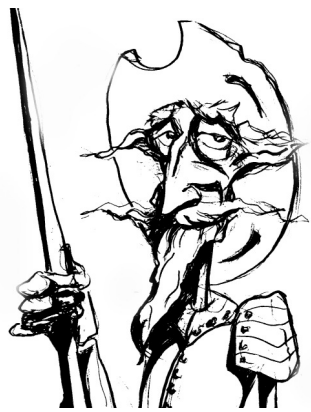

Recibido con pedido de publicación el 5 de abril de 2020

Aceptado para su publicación el 10 de junio de 2020

Versión definitiva recibida el 23 de julio de 2020

María Juliana Gandini, Universidad Nacional de Luján, Universidad de Buenos Aires, Instituto de las Culturas, Buenos Aires, Argentina; e-mail: gandini.juliana@gmail.com

* Agradezco los comentarios de evaluadores y evaluadoras de Prohistoria.

Esta obra se publica bajo licencia Creative Commons. Atribución-NoComercial-CompartirIgual (cc) EY-NC-SA 4.0 Internacional

Gandini, María Juliana “Estrategias para traducir la alteridad: los nativos rioplatenses entre sus testigos directos y la Historia general de los hechos de los castellanos de Antonio de Herrera y Tordesillas (1536-1615)", Prohistoria, Año XXIII, núm. 34, dic. 2020, pp. 75-104. 


\section{Introducción}

El establecimiento de vínculos efectivos entre espacios geográfica y culturalmente distantes entre sí, como lo fueron Europa y América con anterioridad a los viajes colombinos requirió de enormes esfuerzos que no se limitaron a la construcción de un aparato colonial de explotación y control de territorios y poblaciones nativas. Implicaron además el despliegue de estrategias representacionales y científicas como la apelación a la tradición clásica y bíblica europea, el desarrollo de mecanismos de producción y validación de información empírica y el surgimiento de nuevos tipos textuales y tópicos literarios asociados a experiencias en ultramar.

En este trabajo, nos ocuparemos de analizar la producción de representaciones sobre dos sociedades nativas del Río de la Plata, ${ }^{1}$ los guaraníes y los agaces, en dos contextos disímiles pero vinculados. Primero, entre los testimonios directos de la temprana conquista de la región (1536-1545); luego, en la escritura historiográfica del más prolífico de los cronistas reales de Indias, Antonio de Herrera y Tordesillas (1549-1626). Analizando tanto los textos derivados del contacto directo con los nativos rioplatenses como La historia general de los hechos de los castellanos en las islas i tierra firme del mar océano (Madrid, 1601-1615), pretendemos iluminar los diversos procesos de producción, circulación, recepción y resignificación de las representaciones producidas sobre las sociedades nativas de la región, con el fin de identificar las operaciones que sus autores realizaron para comprenderlas y comunicarlas.

Las representaciones sobre los nativos del Río de la Plata desarrolladas a partir de su primera conquista fueron originalmente producto del encuentro efectivo entre los invasores españoles y sus sociedades nativas. Los autores de estos testimonios fueron gobernadores, lenguas, soldados, capitanes y escribanos, todos agentes coloniales alejados en distintos grados de las convenciones de la alta cultura del renacimiento y más ligados a las tradiciones escriturarias de los registros judicial y administrativo. Por ello, las representaciones que produjeron a propósito de los nativos platenses se conformaron fundamentalmente en el registro manuscrito de la administración colonial. En él se basó también la primera historia édita de la región, los Comentarios (Valladolid, 1555) de Álvar Núñez Cabeza de Vaca (c. 1490- c. 1560), su discutido gobernador entre 1542 y 1545, que apelando al registro

\footnotetext{
${ }^{1}$ Si bien en la actualidad este término refiere únicamente a los territorios próximos al curso del Río de la Plata, en el temprano siglo XVI se empleó para designar aquellos extendidos en torno a los ríos Paraná y Paraguay desde la costa Atlántica. Seguiremos este uso y lo combinaremos con la referencia al antiguo Paraguay para designar de forma más específica el área en torno a la ciudad de Asunción.
} 
historiográfico buscó defender su propia memoria histórica frente a los desgraciados eventos de la gobernación (Adorno y Pautz, 1999: 97). ${ }^{2}$

En cambio, el cronista real desarrolló sus tareas en un ámbito cortesano, por lo que sus credenciales y prácticas eruditas lo inscribían plenamente en los círculos del humanismo tardío europeo. Herrera nunca visitó los territorios que refería en su Historia general, pero tampoco lo necesitaba, ya que su objetivo era presentar desde la corte del monarca y para públicos españoles y europeos, una narración coherente y oficial de los eventos que se extendían desde los descubrimientos colombinos hasta la década de 1540 (Kohut, 2010: 177).

Dada la naturaleza dispar de las fuentes consideradas, la atención dedicada en ellas a los nativos rioplatenses no puede ser más que disímil. En los texto de los protagonistas de la primera conquista de la región, el interés en lo que nosotros podríamos llamar etnografía es profuso y casi ubicuo, lo cual se explica porque un conocimiento adecuado de las costumbres de los nativos era una condición necesaria para la subsistencia del enclave colonizador (Rowe, 1964: 3). En el caso de los Comentarios de Cabeza de Vaca, las descripciones de sobre la forma de vida de las distintas sociedades nativas tampoco son escasas y se vinculan tanto con la defensa de sus actuación en el Río de la Plata como con el interés de dotar a la narración de atractivas referencias para sus lectores. En cambio, en el caso de Herrera, la información de tipo etnográfica es más escasa, de acuerdo a su interés historiográfico-político centrado los "hechos de los

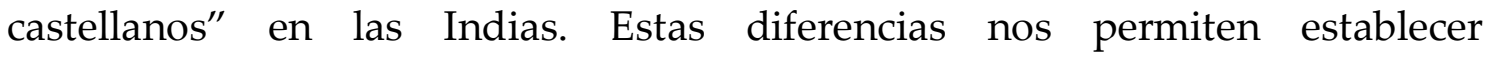
comparaciones productivas que enriquecen la comprensión de las formas en que las características de las sociedades nativas americanas fueron entendidas, descriptas y comunicadas en distintos contextos españoles y europeos.

Las representaciones producidas a propósito de los nativos rioplatenses en los dos contextos señalados serán abordadas a través del concepto de traducción cultural. El mismo, con una larga historia que comienza con la antropología social británica, goza actualmente de un amplio favor en los estudios culturales, en tanto que permite conceptualizar traspasos de sentido entre culturas. Es por ello que resulta una herramienta valiosa para analizar tanto los resultados de contactos interculturales como sus procesos de recepción.

Las operaciones de traducción, comprendidas en un sentido amplio, serán estudiadas tomando como unidades de análisis las distintas

\footnotetext{
2 El título de la obra es Comentarios de Alvar Nuñez Cabeza de Vaca, adelantado y gouernador de la prouincia del Rio de la Plata. Scriptos por Pero Hernandez.... Este texto se halla integrado en un volumen a una segunda edición de la obra previa de su autor, La relacion que dio Alvar Nuñez Cabeça de Vaca de lo acaecido en las Indias en la armada donde iva por gobernador Panphilo de Narbaez...(Zamora, 1542). El volumen vallisoletano se editó como La relacion y comentarios del Gobernador Alvar Nuñez Cabeça de Vaca, de lo acaecido en las dos jornadas que hizo a las Indias. Sobre los problemas de autoría de Comentarios, véase El Jaber (2012) y Gandini (2012).
} 
representaciones realizadas sobre los guaraníes y los agaces del Río de la Plata. Por representación, comprendemos un acto de creación de sentido determinado tanto por la capacidad creativa de los individuos como de las normas que definen lo pensable y decible en una sociedad determinada en sus instancias de producción y recepción (Chartier, 1991: IX-X). El concepto considerar además la relación problemática del acto de representar con los fenómenos que la representación refiere, sea en una dimensión sustitutiva o mostrativa (Marin, 1988: 63). En efecto, no hay entre ambas instancias una relación transparente, sino un vínculo construido e históricamente determinado que puede analizarse críticamente (Ginzburg, 2010 [2006]: 404-410).

Las operaciones de traducción pueden comprenderse como una de las formas en que las representaciones se producen, circulan y cambian de sentido. Constituyen en sí mismas actos de creación de sentido que involucran experiencias directas, procesos de selección, re-contextualización, escritura y reescritura. Estos procesos nos permiten comprender cómo se enlazaron, sutil pero firmemente, la distante frontera rioplatense y los eruditos lectores europeos del cronista oficial del rey español.

\section{Traducciones entre la lengua, la cultura y las representaciones}

¿Cómo aplicaremos el concepto de traducción de cultural a nuestro análisis? A primera vista, no cabrían muchas dudas respecto de que las interacciones entre nativos americanos y europeos de distintas procedencias requerirían de un ejercicio de traducción, tanto en su estricto sentido lingüístico como en uno más amplio de tipo cultural. También podríamos entender como una traducción cultural, aunque cubriendo una distancia menor, el pasaje de un texto sobre el Nuevo Mundo entre lenguas europeas, sobre todo en un contexto de crisis religiosa y política como el que vivió Europa durante la modernidad clásica. Hay que considerar además que estos pasajes entre lenguas implicaban un reencuadramiento del texto traducido en términos de género, proyecto intelectual-editorial y públicos lectores ajenos a sus parámetros originales (Chartier, 2016 [2015]; López de Mariscal, 2004; Gandini, 2013).

Sí podrían caber más dudas si consideramos actores y procesos de producción de sentido que, aunque separados por grandes distancias sociales, tuvieron lugar en el seno de una misma sociedad o de dos instancias más o menos próximas de ella en el tiempo. ${ }^{3}$ En nuestro caso, esta distancia cultural más reducida se establecería entre un capitán o un lengua internado en el Paraguay a mediados del siglo XVI respecto del historiógrafo cortesano y de su público lector ¿Constituyen las operaciones realizadas por el cronista para

\footnotetext{
${ }^{3}$ Queda pendiente considerar el uso del concepto para referir traspasos entre el registro visual y el discursivo o entre distintos registros escritos, casos para los cuales se ha empleado con éxito la noción de trasposición (Genette, 1989 [1962]; Kwiatkowski, 2017).
} 
valerse del registro testimonial de la primera conquista del Río de la Plata casos de traducción cultural?

Con el fin de despejar esta duda, es necesario un somero análisis del concepto y su aplicabilidad. Para empezar, la traducción en su sentido más generalizado se encuentra anclada prácticas lingüísticas, refiriendo a un traspaso de sentido entre lenguas. Sin embargo, los lingüistas que sentaron las bases de lo que luego sería la teoría de la traducción ya consideraban que el acto de traducir superaba ese estrecho marco. Roman Jakobson (1959: 233) afirmó que además de la traducción interlingüística, podían distinguirse la traducción intralingüística (dentro de una misma lengua a través de la paráfrasis) y la transmutación (el cambio de código entre signos verbales y no verbales.

Esta ampliación de los fenómenos incluidos dentro de la traducción ha sido abonada en las décadas siguientes. Así, George Steiner señaló que la propia capacidad cognitiva humana es en sí un acto de traducción, que se despliega en el desarrollo del pensamiento personal, el entendimiento interpersonal o el pasaje entre leguas (1980 [1975]: 21-70). Esta línea de análisis ha sido recuperada y ampliada por parte de la teoría antropológica heredera de los estudios de Franz Boas (1858-1942) y E. E. Evans-Pritchard (1902-1973) (Asad, 1986: 141-164; Leavitt, 2015: 272-275), la cual afirma que la traducción entre culturas constituye la herramienta por antonomasia del conocimiento etnográfico. Una compilación reciente ha dado un paso más allá, abordando a la traducción como un principio epistemológico general que permitiría establecer nuevas bases para una teoría de la cognición humana (Hanks y Severi, 2015: 16).

Nuestro análisis se ubicará, si se quiere, en un espacio intermedio. Si bien abordará las operaciones de traducción más allá del campo lingüístico, no se internará en las implicancias cognitivas que pueden atribuírsele. El foco de nuestra atención estará puesto en definirla como un mecanismo capaz de producir el entendimiento de fenómenos socio-culturales. Por tanto, podemos definir como traducción cultural a las operaciones que hacen posible comprender tanto una sociedad por otra, como un grupo por otro dentro de ella. El ejercicio supone la existencia de una diferencia percibida, de mayor o menor grado, entre las formas de vida, pensamiento y expresión del grupo que se pretende explicar o describir y aquellas de sus receptores, volviendo inteligibles prácticas e ideas políticas, económicas, sociales y culturales ajenas en los términos de quienes realizan la traducción o la reciben.

De esta forma, la traducción cultural no se limita a un traspaso de lenguas, aunque puede incluirla, ya que la capacidad metalingüística de la lengua (Jakobson, 1959: 234) para explicar, reformular, glosar, definir o describir constituyen actos de traducción. Lo mismo ocurre cuando encontramos distancias temporales, de clase, género, estatus u ocupación -por solo mencionar algunos casos- que separan al grupo traducido del grupo traductor 
dentro de una misma comunidad lingüística (Steiner, 1980 [1975]: 49-70; Ricoeur, 2009 [2004]: 50-52; Hanks, 2015: 26; Leavitt, 2015: 260-261).

Tanto la traducción lingüística como la cultural se enfrentan con la paradoja de que lenguas y culturas son inconmensurables; no obstante ello, las traducciones son ubicuas. Si bien no existen equivalencias perfectas entre sistemas lingüísticos o culturales distintos, siembre ha sido posible traducir (Ricoeur, 2009 [2004]: 34, 64; Ginzburg, 2011 [1998]: 159). Según Ricoeur, es el propio acto de traducir el que construye la conmensurabilidad que hace posibles las traducciones (2009 [2004]: 70-74), produciendo los equivalentes a través de glosar de las diferencias, comparar, describir, detectar "intraducibles" o generar vocabularios y clasificaciones. ${ }^{4}$ Así, la traducción entre lenguas o culturas aparece más como un "trabajo que individuos y grupos deben realizar para domesticar lo ajeno" (Burke, 2009: 58) y que lejos de ser un proceso terminado, puede asimilarse a "un compromiso desprolijo, que involucra pérdidas o renunciamientos y deja lugar a renegociaciones" (2007: 9). ${ }^{5}$ Estas reflexiones permiten abordar los actos de traducción-mediación como el resultado de una encrucijada entre factores más estructurales (tradiciones culturales, adscripción socio-institucional, experiencias previas) y otros más coyunturales (relaciones novedosas entre las partes, circunstancias específicas del contacto, individuos implicados en el proceso), que además conserva el dinamismo de toda experiencia relacional.

Bajo las consideraciones realizadas, creemos que es posible analizar tanto la producción de representaciones de los nativos del Río de la Plata por sus testigos directos como aquellas contenidas en la Historia general de Herrera como operaciones de traducción cultural de distinto tipo. Unas, centradas en un entendimiento transcultural directo, resultado del contacto entre sociedades completamente ajenas entre sí. La segunda, concentrada en cambio en la producción de una historia de la conquista aceptable para la corona y entendible para los públicos lectores que estaban removidos tanto del conocimiento directo del mundo americano, como de las fuentes primarias con las que sí trabajaba Herrera.

Esto no quiere decir que las representaciones y las traducciones culturales producidas por los agentes coloniales españoles y el cronista real hayan sido adecuadas respecto de la forma en que vivían o se comportaban las sociedades nativas del Río de la Plata aludidas. El entendimiento intercultural es siempre un desafío que, como la traducción a la que engloba, encuentra

\footnotetext{
${ }^{4}$ Estas operaciones resultan análogas a las que François Hartog definió como "retórica de la alteridad" (Hartog, 2003 [1980]: 207)

${ }^{5}$ Incluso, una mala traducción pudo bridar una base de entendimiento inédita para dos grupos de ajenos entre sí, por ejemplo como refiere Richard White para las relaciones establecidas entre colonos franceses y nativos de los Grandes Lagos entre el siglo XVII y el XIX (White, 1991 [2001]).
} 
puntos ciegos, "intraducibles" o aún peor, "imperceptibles", que son la marca de la diferencia cultural (Leavitt, 2015: 263-272; Burke, 2009: 59-60 y 2007: 10). Si se considera además que estamos analizando aquí una situación colonial, la perspectiva de entendimiento empeora, ya que a ojos de los colonizadores europeos existía una clara jerarquía en la que las sociedades nativas americanas ocupaban un lugar subalterno. Pero todo esto no vuelve estéril ni los intentos que los europeos de la modernidad clásica realizaron por comprender otras culturas ni su análisis en la actualidad. Por un lado, por el valor que estos testimonios, debidamente analizados y cotejados con otras evidencias textuales y materiales, tienen respecto del conocimiento de los grupos humanos que refieren (Ginzburg, 2010 [2006]: 407 y 456; Schwartz, 1994: 2-3). Por el otro, por lo que revelan respecto de los "filtros culturales" (Ginzburg, 2010 [2006]: 145) que utilizaron los europeos en el contexto de la expansión ultramarina, en sus intentos de comprender y comunicar la dramática expansión de sus horizontes humanos y naturales. Si bien este último constituye el problema central de nuestro trabajo, creemos importante resaltar que ello no implica renunciar a la evasiva dimensión referencial de nuestras fuentes, anclada tanto en poderosas tradiciones culturales como en situaciones específicas de contacto intercultural. De allí que tomaremos como marco de análisis la historia cultural. En su doble capacidad para explicar contextos y casos específicos, nos permite reconstruir las estrategias particulares que sustentaron distintas operaciones de traducción cultural que explican la producción y la re-significación de representaciones sobre las sociedades nativas del Río de la Plata.

\section{Los nativos del Río de la Plata y sus testigos directos}

En agosto de 1537 un grupo de hombres conducidos por el capitán Juan de Salazar (1508-1560) llegó al antiguo Paraguay. Buscaban los rastros de sus compañeros, que habían partido el año anterior del puerto de Santa María de los Buenos Aires, en la boca del Río de la Plata. El mismo, fundado por el adelantado Pedro de Mendoza en 1536, prometía el acceso a las riquezas metalíferas que suponían tierra adentro, según habían comunicado las expediciones de Sebastián Caboto (1477-1557) y Diego García de Moguer (c. 1484- c. 1544) (Guerin, 2000).

Pero la expedición de Mendoza rápidamente se disolvió por los episodios de hambre que signaron las primeras instancias de la conquista del área rioplatense. El avance río arriba obedeció tanto a la búsqueda de los metales preciosos como a la acuciante necesidad de hallar fuentes seguras de alimentos.

Las encontrarían en poder de los carios, una parcialidad guaraní que habitaba en la confluencia de los ríos Paraguay y Pilcomayo. Prósperos agricultores de roza (Silva Noelli, 2004; Melià, 1999), se mostraron interesados 
en intercambiar alimentos y algunas pocas mujeres por herramientas de hierro, como anzuelos y hachas, que veían en poder de los extraños visitantes (Roulet, 1993: 115-119). Este contacto pacífico inicial, fundado en las necesidades de españoles y nativos permitió que Salazar fundara un fuerte en las cercanías de las aldeas carias, que se convertiría en 1541 en la ciudad de Nuestra Señora de la Asunción.

Pero los guaraníes no eran los únicos asentados en la región. Para su disgusto, debían compartir territorios que consideraban propios y exclusivos (Susnik, 1982: 20) con otras sociedades (Carvalho, 1992; Susnik, 1983), como lo eran los agaces del río Pilcomayo y el curso inferior del Paraguay. Si bien practicaban ocasionalmente la agricultura, su subsistencia se basaba fundamentalmente en la pesca y la caza, siendo considerados verdaderos señores del río. ${ }^{6}$ Aunque guaraníes y agaces solían tener enfrentamientos violentos, estos no impedían la realización de intercambios regulares y más pacíficos entre unos y otros.

Esta compleja situación, a la que se sumarían los invasores cristianos, fue el origen de las diversas representaciones formuladas sobre los guaraníes y agaces en el registro judicial, administrativo e historiográfico de sus testigos directos europeos. Las mismas serán consideradas como operaciones de traducción cultural, en las que los conquistadores del Río de la Plata intentaron desarrollar un entendimiento de sus sociedades nativas con el doble fin de asegurar la instalación colonial y convencer a distintas autoridades peninsulares (el Consejo de Indias, el fiscal del rey, diversos círculos cortesanos) de lo apropiado de sus acciones.

Para poder explicar y explicarse las particularidades de guaraníes y agaces, apelaron por supuesto a las ideas y tradiciones antropológicas ancladas en la historia del Viejo Mundo y en los antecedentes más recientes de la conquista de otras partes del Nuevo. Pero también, debieron reconocer sus rasgos particulares, evidentes a partir de una convivencia tan inédita como cotidiana. La traducción aparece así como una instancia necesaria para dar cuenta de lo nuevo apelando a lo ya conocido (Mignolo 1980: 61; Hartog 2003 [1980]: 207), aproximación que permite reconstruir el primer capítulo rioplatense de la formación de representaciones sobre la alteridad cultural americana.

Una de las formas más importantes en que se articuló la traducción de las características propias de guaraníes y agaces en la primera conquista del Río de Plata fue la estructuración de sus especificidades culturales bajo la forma de

\footnotetext{
${ }^{6}$ Los guaraníes-carios debían también compartir el espacio con los guaycurúes, una sociedad chaqueña del oeste de Asunción. Más al norte, sobre el río Paraguay, habitaban asimismo los payaguás, pescadores que, como los agaces al sur, controlaban la navegación del río.
} 
una oposición entre agricultores y corsarios-salteadores respectivamente. ${ }^{7}$ Desde la etnografía clásica, describir la forma en que un grupo humano explotaba el medio involucraba una valoración sobre la calidad de su existencia. Indicar que una sociedad realizaba prácticas agrícolas implicaba reconocer su capacidad para intervenir sobre la naturaleza y doblegarla en su beneficio (Pagden, 1993: 6). Desde el punto de vista de las percepciones antropológicas europeas tradicionales, esto las colocaba por encima de aquellos grupos que subsistían base a la caza y la recolección, considerados incapaces de dominar plenamente su entorno. Consecuentemente se consideraba que vivir en asentamientos fijos, en contraposición a la trashumancia, fomentaba una vida social ordenada en cuanto a jerarquías, vida familiar, distinción de prácticas privadas y públicas y control de la violencia y las emociones.

Si bien estas valoraciones eran parte del bagaje cultural europeo, en el contexto americano en general y rioplatense en particular, asumieron nuevos referentes y se acomodaron a los avatares de las relaciones establecidas entre invasores y nativos. Así, aunque las referencias a las actividades productivas conservaron su carga valorativa, funcionaron también como mecanismo de evaluación de las condiciones materiales de subsistencia. Entre la evaluación estratégica de los recursos, las tradiciones etnográficas del Viejo Mundo y la experiencia directa de comportamientos y pautas culturales desconocidas hasta entonces por los europeos, las referencias a la forma de subsistencia de los nativos rioplatenses funcionaron como instancias de traducción que permitieron a los agentes coloniales locales y a sus destinatarios peninsulares evaluar las potencialidades productivas de los indios, sus posibles reacciones y expectativas y la posibilidad de establecer alianzas con ellos. De esta forma, se fueron sedimentando representaciones sobre los nativos rioplatenses ancladas simultáneamente en expectativas culturales y experiencias directas.

Sin duda, los conquistadores establecieron los lazos más firmes y duraderos con los guaraníes, en especial con los carios de las cercanías de Asunción. Los mismos proporcionaron los excedentes para sostener la conquista, los guerreros para explorar el Chaco y las mujeres devenidas forzosamente criadas, trabajadoras y madres (Susnik, 1965: 10). A cambio, recibieron las herramientas de hierro que multiplicaron la productividad de sus rozas y se integraron al violento frente expansivo que movilizaban los conquistadores. Esta convergencia estratégica, solo viable mientras los cristianos no pudieron imponerse unilateralmente, condicionó tanto las representaciones producidas sobre los guaraníes como aquellas de sus vecinos.

\footnotetext{
7 La elección de las categorías utilizadas para abordar los mecanismos de representación y traducción de las sociedades rioplatenses se nutre de los conceptos que aparecen en las fuentes de su temprana conquista y colonización. Además de las aquí reseñadas, se han detectado también la oposición entre la guerra y el "servicio" de los guaraníes.
} 
Así, el capitán Salazar destacó que los carios eran "gente que sembraba y cogía [...] y visto lo susodicho, asentaron paz e concordia con los dichos indios de esta tierra". ${ }^{8}$ En la misma línea, Álvar Núñez Cabeza de Vaca encareció en Comentarios a los guaraníes, afirmando que "son labradores, que siembran dos veces en el año maíz, y asimismo siembran cazabi, crían gallinas a la manera de nuestra España, y patos" (Núñez Cabeza de Vaca, 1555: LXIIv-LXIIIr), agregando en una de sus probanzas que eran "gente doméstica, amiga de cristianos, aparejados para con poco trabajo a traerlos al conocimiento de nuestra santa fe católica." ${ }^{\prime 9}$

La agricultura no solo era la base material que sustentó la convergencia entre guaraníes y conquistadores, sino que permitió construir una representación sobre ellos útil a los agentes coloniales rioplatenses $\mathrm{y}$ significativa para sus receptores peninsulares. En efecto, los lectores de los textos producidos por los testigos del Río de la Plata encontrarían que aquella lejana conquista se cimentaba en una población nativa industriosa, sedentaria y capaz de producir alimentos para sí y para sus nuevos señores, operación de traducción cultural que se realizó refiriendo su modo de subsistencia. Paralelamente, hacía ver como especialmente graves las crueldades perpetradas sobre estos nuevos súbditos, por lo que la representación de los guaraníes como una sociedad de ordenados agricultores apareció muchas veces en el centro de las contiendas judiciales que jalonaron el período analizado.

Esta representación halagüeña coexistió sin embargo con un rasgo ciertamente más preocupante: los guaraníes eran también notorios caníbales. En efecto, las sociedades tupí-guaraníes practicaban una forma de canibalismo ritual vinculado con la guerra de venganza (Susnik, 1982: 53; Carneiro Da Cunha y Viveiros de Castro, 1985). A partir de las sensacionalistas descripciones de Amerigo Vespucio (1454-1512), las referencias a la antropofagia de los nativos del Mar Océano austral era un dato habitual de la historia de la conquista, la cosmografía y los relatos de viaje (Lestringant, 1997 [1994]). Estas representaciones estaban ligadas a ideas clásicas y cristianas europeas sobre los antropófagos, seres antisociales que devoraban a otros hombres por hambre y que confundían el orden natural al alimentarse de sus semejantes (Pagden, 1986 [1982]: 86). Pero a diferencia de esta tradición y de las representaciones que inspiró, los documentos de la primera conquista del Río de la Plata describían las prácticas antropofágicas de los guaraníes como un elemento más de una convivencia cotidiana, sin entrar en conflicto con su descripción como agricultores y amigos de los cristianos. ${ }^{10}$

\footnotetext{
8 Archivo General de Indias (AGI), Patronato, 93, N. 11, R. 1, f. 9v, Asunción, febrero de 1545.

9 AGI, Justicia, 1131, Pieza 21, f. 4r, Madrid, 7 de diciembre de 1545.

${ }_{10}$ Por supuesto fue una práctica condenada por los conquistadores, quienes sin embargo no podían controlarla dada la relación de fuerzas existente en estos primeros años de instalación colonial. Por ejemplo, Cabeza de Vaca instó a los jefes carios a que abandonaran la costumbre,
} 
Cabeza de Vaca, por ejemplo, no terminaba de presentarlos como domésticos productores de plantas y animales en sus Comentarios cundo agregó que "comen carne humana, así de indios sus enemigos, con quién tienen guerra, como de cristianos, y aun ellos mismos se comen unos a otros" (Núñez Cabeza de Vaca, 1555: LXIIIr). Pero esta constatación no los volvía enemigos capitales, como se supondría, por dos razones. Primero, porque la débil conquista necesitaba la comida, pero también, el potencial bélico de los guaraníes; segundo, porque se sabía que el canibalismo practicado por ellos no era una práctica alimentaria o descontrolada, sino que estaba atada al principio de la guerra: mientras fueran aliados, los cristianos quedaban al margen de la costumbre. Un testimonio de esta "tolerancia” práctica al canibalismo apareció en una relación de Pero Hernández, secretario de Cabeza de Vaca. Al denunciar a la facción que lo había removido, afirmó que Domingo de Irala (1509-1556) y los oficiales reales habían "dado licencias a los indios principales naturales de esta tierra, siendo cristianos, que comiesen carne humana matando en su casa indios y enemigos suyos. Gonzalo de Mendoza pidió licencia para Timbuay, su suegro, y mató a un agaz y vinieron a comerlo más de dos mil indios."11

El piloto Juan Sánchez de Vizcaya, menos amigo del gobernador, destacó que aquel había entregado prisioneros agaces "a los indios nuestros amigos [los carios] para que los matasen y creo que los comieron, porque esta generación de indios naturales de la tierra comen carne humana." ${ }^{12}$ En un último ejemplo, el clérigo Francisco de Andrada comunicaba al rey las duras condiciones de su prédica "doctrinando a estos paganos la doctrina de dios y reprendiéndoles sus vicios y malas costumbres que eran comer carne humana y copularse carnalmente con sus parientes y otras malas costumbres..."13

Ser caníbal en el Río de la Plata temprano-colonial no implicaba, por tanto, estar excluido de la humanidad; ni siquiera implicaba ser objeto de guerra justa o de persecución por parte de los cristianos. Por el contrario, los guaraníes eran aliados, parientes y receptores de la palabra divina, un raro tipo de antropófago civil que no existía en las tradiciones antropológicas del Viejo Mundo. La capacidad de traducir este extraño caso para públicos peninsulares se expresó en el lenguaje de la necesidad: porque son cultivadores (y por ello también, civiles) es que puede sostenerse la conquista aliándose a ellos, considerando que sus prácticas antropofágicas se limitaban a sus enemigos. Esta inusual combinación de rasgos tradicionalmente opuestos en las tradiciones antropológicas europeas habilitó la construcción de una

en AGI, Justicia 1131, Pieza 2, ff. 111r-112v, Asunción 29 de septiembre de 1542, hecho también referido en Comentarios (Núñez Cabeza de Vaca, 1555: LXXIIIv)

${ }^{11}$ AGI, Patronato, 29, R. 5, f. 8r.

12 AGI, Justicia, 1131, Pieza 17, ff. 1055r-1055v.

${ }^{13}$ AGI, Justicia, 1131, Pieza 15, f. 969v, Asunción, 1 de marzo de 1545. 
representación novedosa de la conducta humana a partir de la experiencia concreta de la conquista del Río de la Plata.

Frente a esta curiosa contraposición de rasgos y actitudes, la representación de los agaces resulta menos matizada. Su capacidad para controlar los desplazamientos río abajo, la rápida movilidad que los caracterizaba, sus relaciones previas (a menudo conflictivas) con los guaraníes y su capacidad para modular las interacciones con los conquistadores, les permitían una amplia independencia. Difíciles de controlar, reacios a entrar en relaciones condicionantes con los españoles y sin tener intereses comunes con ellos, la forma de vida de los agaces fue traducida en el lenguaje negativo del saqueo y la traición. Las representaciones construidas sobre ellos, extendidas en la mayor parte de las fuentes testimoniales de la temprana conquista del Río de la Plata, utilizaron las características de su forma de vida como cazadoresrecolectores para construirlos como pertinaces enemigos: la misma les permitía una peligrosa autonomía, a la vez que se relacionaba orgánicamente con las ideas etnográficas tradicionales de los europeos respecto de las sociedades cazadoras-recolectoras.

Los agaces fueron entonces caracterizados como salteadores, piratas o corsarios, vocablos que referían al robo y el homicidio por agua y tierra. ${ }^{14} \mathrm{Si}$ bien era cierto que solían atacar las aldeas guaraníes, la lógica de estos ataques no podía subsumirse a aquellas de propiedad y control territorial que los cristianos traían Europa y deseaban imponer en el Río de la Plata. Asimismo, la idea de una paz inquebrantable les era ajena ya que entendían los enfrentamientos como parte de una dinámica más amplia de relación con los carios. En cambio, los conquistadores atribuyeron esto a una naturaleza traicionera en los canoeros, traduciendo sus acciones a través de la violencia y el saqueo.

Lope de Ugarte, un soldado que trajinó el Río de la Plata desde 1536, declaró ante los oficiales de la Casa de la Contratación que los agaces eran "una generación de indios que como alabares traen sus casas y haciendas y se mudan de unas partes a otras y navegan en canoas en el río y siempre habitan en la ribera del río, se mantienen de pesca y caza..."15 El comparar a los agaces con alabares (i. e., árabes) constituía una acción de traducción que permitía que quienes recibieran la noticia en España pudieran comprender rápidamente que eran nómades y no cultivaban (hecho que los colocaba ya bajo una luz negativa)

\footnotetext{
${ }^{14}$ Sebastián Covarrubias define a un corsario como quien "anda a robar por la mar. Pirata" (Covarrubias, 1611: 244r), mientras que saltear queda definido como "robar en el campo, delito atrosísimo, especialmente junto con quitar al caminante la hacienda, le quitan la vida. Este género de ladrones dichos salteadores, suelen tener por guarida los bosques espesos en las montañas y así de la palabra saltos, que vale bosque, se dijo saltear y salteador" (Covarrubias, 1611: 20r).

${ }_{15}$ AGI, Justicia, 1131, Pieza 17, f. 1042v, Sevilla, 27 de agosto de 1545.
} 
y que podían compararse por ello con la temida alteridad musulmana, cuyas representaciones -si no universalmente negativas- invocaban temores $\mathrm{y}$ ansiedades varias veces seculares en península Ibérica.

Cabeza de Vaca, por su parte, también produjo representaciones negativas sobre los agaces, informando que

“eran y son gente belicosa, indómita e atrevida a vuestro real servicio y justicas, son robadores y salteadores e ningún oficio ni ejercicio tienen sino matar y robar e saltear e andar hechos corsarios, matando e inquietando así cristianos como a los otros indios que están debajo de la obediencia de vuestra alteza e no guardan fe ni palabra de amistad ni tregua..."16

Aquí ni siquiera se mencionaron sus medios de vida, sino que se los presenta como "corsarios" que subsisten de la rapiña de lo ajeno y comprometen la seguridad de la conquista. Sabemos que las referencias habituales a las "traiciones" de los indios traducen en realidad la amplia agency que las sociedades nativas sostuvieron, en distintos grados y modos, durante todo el período colonial. Más ostensible en los primeros momentos de instalación y en zonas fronterizas, la capacidad de los nativos de evadir el control de los conquistadores fue generalmente traducida en el lenguaje de la traición. Así lo hizo Cabeza de Vaca, preocupado además por las acusaciones de sus contrarios respecto a haberse excedido en la guerra realizada contra los canoeros.

Pero esta representación negativa de los agaces no puede reducirse a una mera justificación política. Juan de Salazar, personaje de peso propio en la conquista, también los refirió en tonos similares. En una colorida descripción de los eventos ocurridos cuando quedó interinamente a cargo de Asunción en 1543-44, Salazar destacó que los agaces,

"han venido a saltear y les mataban muchos indios de los amigos y cristianos nuevamente convertidos y los llevaban presos y de las haciendas de los cristianos llevaban las indias que andaban sembrando y limpiando los maíces y a las unas mataban y a las otras llevaban cautivas y las traían a rescatar por el río por ropa, y planchas, y hachas, y otros rescates, $\mathrm{y}$ mucho maíz y mandioca, y los cristianos ni los indios no eran señores de ir a pescar al río con temor de ellos e asimismo de noche robaban los maíces y los destruían y de ellos recibían grandes injurias y molestias y cuanto mejores palabras los cristianos les daban, y más los requerían, más se ensorbebecían

\footnotetext{
16 AGI, Justicia, 1131, Pieza 1, f. 67r, Valladolid, 28 de marzo de 1551. Cabeza de Vaca caracterizó de esta forma a los agaces en otras declaraciones y también en sus Comentarios (1555: LXXIVr).
} 
y decían que era de miedo de ellos y así se alababan de ello a otras generaciones"17

El testimonio de Salazar volvió a resaltar la oposición entre los guaraníes, cultivadores y aliados, y los agaces, salteadores y traicioneros. En su descripción, la piratería y los asaltos permiten resumir y explicar no solo las relaciones de cooperación o enfrentamiento que podrían establecerse con los nativos del Río de la Plata, sino también las consecuencias morales y conductuales de su capacidad o no de cultivar la tierra.

De este modo, las referencias a las distintas formas en que guaraníes y agaces explotaban el medio que los rodeaba permitía explicar la materialidad sobre la cual podía sostenerse la conquista; pero ello, además, traducía y hacía comprensibles las expectativas de comportamiento y relación sobre las alteridades culturales que los conquistadores habían encontrado del otro lado del Mar Océano. Las mismas se relacionaban tanto con las viejas tradiciones etnográficas europeas como con las experiencias concretas vividas junto a (o en contra de) las sociedades nativas rioplatenses, percibidas a partir de una convivencia forzada y cotidiana. Así, la representación novedosa de los cultivadores-amigos-caníbales y la menos original de los pescadores-enemigoscorsarios permitieron la traducción tanto de las costumbres de carios y agaces, como de las relaciones que podían establecerse con ambos. Estas representaciones sobre los nativos platenses llegarían, como veremos en el apartado siguiente, a lectores impensados por sus productores originales.

\section{El cronista real como traductor de la primera conquista rioplatense}

Entre ellos se encontró el cronista real Antonio de Herrera y Tordesillas, quien utilizó sistemáticamente documentación manuscrita de archivo (además de célebres obras éditas) para componer su Historia general de los hechos de los castellanos. La síntesis constituyó una obra de referencia para el conocimiento del mundo americano hasta entrado el siglo XVIII, ${ }^{18}$ por lo que variados públicos europeos se toparon con distintos testimonios de primera mano de las Indias camuflados en la elegante prosa del historiógrafo.

Como cronista mayor, cargo que ocuparía desde 1595 hasta su muerte, Herrera estaba obligado a producir la versión oficial de la corona española sobre los eventos de la conquista de las Indias. Esta debía considerarse creíble no solo dentro de España, sino también entre públicos europeos que no necesariamente favorecían la presencia española en ultramar ni su proyección europea (Chartier, 2016: 89-122). Para ello, Herrera se concentró en resguardar

\footnotetext{
17 AGI, Justicia, 1131, Pieza 18, f. 1078r, Madrid, 26 de junio de 1546.

18 Considérese para ello sus reediciones en latín, francés y alemán durante los siglos XVII y XVIII (Cuesta Domingo, 1998 y 2007: 123) y la edición en castellano de Madrid (1726).
} 
la acción y consecuentes derechos de la corona española en Indias denunciando, en cambio, las "desviaciones" individuales de los conquistadores (Kagan, 2009: 176-178). Esta “distribución inteligente de la culpa histórica" (Brendecke, 2016 [2012]: 440) logró un efecto de neutralidad, ya que si bien se defiende siempre el derecho de los reyes castellanos sobre las Indias, no se ocultan tampoco las atrocidades que caracterizaron su conquista.

Pero el éxito de la obra de Herrera se debió, también, a que realizó exitosamente distintas operaciones de traducción cultural para comprender y hacer comprender la historia de la conquista de las Indias. En efecto, las diferencias de experiencia, educación, intenciones y posición social existentes entre los testigos directos del Nuevo Mundo y sus lectores europeos exigían otras elecciones en el vocabulario, las referencias y la forma de comunicar el mundo americano.

El caso de la primera conquista del Río de la Plata ocupa un lugar marginal en la Historia general, acompañando la escasa importancia que la región revestía para el momento en que Herrera componía su obra. La narración de sus eventos, discontinua por la organización analística de la obra, se encuentran distribuida entre las décadas quinta (libro 9, cap. 10; libro 10, cap. 10), sexta (libro 3, caps. 17-18; libro 7, cap. 5) y séptima (libro 1, cap. 8; libro 2, caps. 8- 9; libro 4, caps. 13-16; libro 7, caps. 14-17; libro 9, caps. 10-12; libro 10 caps. 14-15).

Como en toda la Historia general, la narración de Herrera se sustentó en gran medida en sus fuentes documentales, de las que dependía fuertemente al punto de copiar largos segmentos de ellas de manera más o menos textual (Kagan 2009: 173-175). Esto permitió que numerosos documentos manuscritos que referían de primera mano el mundo americano circularan por fuera del marco institucional español, alcanzando a lectores que sus autores no habrían jamás considerado. ${ }^{19}$ Para el caso del Río de la Plata, podemos destacar tres tipos principales: primero, documentos oficiales, como los que constituyen las capitulaciones e instrucciones dadas o recibidas por las autoridades de la conquista rioplatense; ${ }^{20}$ luego, cartas y relaciones dirigidas al rey, como la

19 Por ejemplo, Herrera utilizó un memorial autógrafo del piloto Diego García de Moguer (AGI, Patronato, 44, R. 2) para narrar una parte de la primera exploración del Río de la Plata, texto que no había circulado previamente por fuera de los canales administrativos españoles (Herrera, 1601: cuarta década, libro I, cap. 1, pp. 1-3).

20 AGI, Indiferente, 415, L. 1, ff. 148v-152v, Toledo, 21 de mayo de 1531; AGI, Charcas, 40, Buenos Aires, 20 de abril de 1537; AGI, Patronato, 185, R. 12, Buenos Aires, 21 de abril de 1537; AGI, Buenos Aires, 1, L. 1, ff. 98r-98v, Valladolid, 12 de septiembre de 1537; AGI, Buenos Aires, 1, L. 1, ff. 107v-108v, Madrid, 18 de octubre de 1539; AGI, Buenos Aires, 1, L. 1, ff. 115r-115v, Valladolid, 20 de noviembre de 1539; AGI, Buenos Aires, 1, L. 1, ff. 124v-129v, Madrid, 18 de marzo de 1540. 
escrita por el expedicionario Francisco de Villalta; ${ }^{21}$ finalmente, Herrera se basó profusamente en los Comentarios de Cabeza de Vaca, referido al comienzo de la obra como una de las autoridades éditas utilizadas en la Historia general. ${ }^{22}$ De esta forma, el cronista construyó una historia abarcativa de la conquista apelando a textos de orígenes e intenciones muy distintos, pero que podía consultar, glosar y combinar por el cargo oficial que ocupaba como cronista oficial.

La importancia de las fuentes primarias en la escritura historiográfica de Herrera determinó que no se desviara demasiado de lo dicho en ellas una vez seleccionadas para integrar su relato. De aquí la importancia de detectar aquellas instancias donde sí lo hizo. En nuestro caso, consideraremos dos de ellas en particular; primero, la utilización de categorías antropológicas alternativas respecto de las utilizadas en las fuentes testimoniales directas de la primera conquista y colonización rioplatense; segundo, la función que cumplen las anotaciones marginales en relación con las descripciones de guaraníes y agaces. Entendemos que estos casos pueden analizarse como operaciones de traducción cultural, en las que Herrera intentó convertir a los nativos del Río de la Plata en una entidad aprehensible para los sus lectores, adaptando su representaciones a su proyecto historiográfico, al tono erudito de su obra y al comentario político-moral que construyó sobre los eventos de la conquista. Los intereses de sus lectores (aprender novedades cosmográficas, conocer los hechos de la conquista o leer atractivos relatos del otro lado del mar) y la preocupación de Herrera por defender la posesión legítima de las Indias por parte de la corona española determinaron así sus elecciones en la traducción de los hechos de la primera conquista del Río de la Plata. La misma se articuló fundamentalmente apelando a la tradición clásica, actualizada a través de una referencia cruzada entre nativos americanos y bárbaros antiguos -de un lado- y entre el imperio romano y la monarquía española -de otro-.

Consideremos primero las nociones antropológicas que aparecen en el texto de Herrera y su relación con aquellas que aparecían en sus fuentes rioplatenses. Al relatar la fundación del puerto de Buenos Aires, Herrera afirmó que no se estableció sobre el cabo Blanco (en la costa de Brasil) ya que allí "no había sino indios caribes, que siempre fueron enemigos y crueles, como bárbaros comedores de carne humana" (Herrera, 1615: década 5, libro 9, cap. 10, p. 272). La referencia a los temibles caribes antropófagos no es, como pareciera,

\footnotetext{
${ }^{21}$ Archivo Histórico Nacional (AHN), Diversos-Colecciones, 24, N. 10, Asunción, 22 de junio de 1556. Villalta había viajado al Río de la Plata con Pedro de Mendoza en 1536. Bartolomé Mitre y Samuel Lafone Quevedo, en su edición del relato de Ulrich Schimdl (1510-1579), habían advertido ya que Herrera había utilizado este documento (1903: 303).

${ }^{22}$ Herrera incluyó a Cabeza de Vaca como uno de los "Autores impresos y de mano que han escrito cosas particulares de las Indias Occidentales", entre los preliminares del primer volumen de la Historia general.
} 
una mera interpolación erudita, ya que la aparecía al comienzo de la carta del expedicionario Francisco de Villalta. En efecto, este último refirió que en el cabo Blanco "no hay indios que sean amigos sino son unos que llaman en otras Indias caribes, estos comen carne humana, son enemigos de los cristianos". ${ }^{23}$

Herrera, siguiendo un mecanismo propio de la traducción, había sin embargo amplificado la descripción, aumentado el campo de referencia dado en su fuente: los caribes son calificados como bárbaros crueles. La noción de barbarie, fundamental en las ideas antropológicas antiguas (Hartog, 2003 [1980]), tuvo un papel vital en la reflexión sobre la diferencia cultural y la naturaleza de la propia identidad europea durante la modernidad clásica. Aunque la misma fue utilizada muchas veces de forma ambivalente y matizada (Kwiatkowski, 2020), en la Historia general prevaleció un sentido polarizador del concepto, que buscaba destacar la distancia entre los "castellanos" y las sociedades nativas americanas que conquistaron (Gandini, 2019: 53-59). En este sentido, la apelación a la barbarie aparece como una forma efectiva para traducir la diferencia cultural a un público que, como el propio Herrera, podía recuperar el contenido clásico del concepto con sus rasgos negativos más salientes: la violencia, la crueldad, la incapacidad para establecer alianzas y, también, el canibalismo.

Villalta también calificó como "caribes" a los carios de Asunción, ${ }^{24}$ pero justamente, su capacidad de producir excedentes agrícolas y relacionarse con los cristianos hizo que los ubicara (como ocurre en el resto de los documentos de la temprana conquista del Río de la Plata) en la nueva categoría antropológica de los caníbales amigos de los cristianos. Herrera retomó esta caracterización, que halló también desarrollada en los Comentarios de Cabeza de Vaca. En efecto, Álvar Núñez ya había asumido el desafío de explicar la especificidad de estos raros antropófagos sociales y cultivadores a lectores que no los conocían de forma directa, por lo que Herrera pudo simplemente replicar lo dicho en Comentarios. ${ }^{25}$ La confianza de Herrera en Cabeza de Vaca no solo se relaciona con su fama como autoridad sobre asuntos de Indias, sino también porque su figura y obras se encuadraron en la defensa de la autoridad real en Indias (Bauer, 2003, 30-76).

No obstante ello, Herrera introdujo algunas modificaciones a lo dicho por Cabeza de Vaca. Al resaltar su experiencia para contener y calmar a un contingente de guaraníes pacíficamente, realizó una ampliación que no aparece en el texto original: "Álvar Núñez, como quien conocía la naturaleza de los bárbaros, con mensajes y presentes los sosegó" (Herrera, 1615: década 7, libro 2,

\footnotetext{
${ }^{23}$ AHN, DC, 24, N. 10, f. 1r.

${ }^{24}$ AHN, DC, 24, N. 10, ff. 2r y 2v.

${ }_{25}$ Compárese la descripción de los guaraníes realizada por Herrera (1615: década 7, libro 2, cap. 8, p. 46) con la de Cabeza de Vaca (1555: LXIIIr).
} 
cap. 9, p. 49). ${ }^{26}$ En la sección original de los Comentarios (Núñez Cabeza de Vaca, 1555: LXIXr) la barbarie no aparece como una caracterización explícita de los guaraníes. En sus textos, Cabeza de Vaca solo mencionó explícitamente el concepto en sus proemios, allí donde se dirigía al rey Carlos V o a su nieto, el infante don Carlos, en un elaborado estilo humanista (Gandini, 2019: 40-41). En el cuerpo de su Relación y de Comentarios, Cabeza de Vaca solo se refirió a los nativos americanos como "indios" o utilizando sus nombres atribuidos, por lo que la referencia a la barbarie de los guaraníes y la oposición que construye con la figura de Cabeza de Vaca es una intervención de Herrera. Esta operación ayudó al cronista a cimentar la idea de una conquista justa (ya que se realizó sobre supuestos "bárbaros") y, mediante el juicio positivo sobre Cabeza de Vaca, establecer el patrón de conducta deseable para los conquistadores. Ambos ejes reaparecen enfáticamente en las notas marginales que el cronista introdujo en el relato de la primera conquista del Río de la Plata.

Las notas en los márgenes se encuentran distribuidas en toda la Historia general. Las mismas pueden dividirse en dos tipos según su función: algunas resumen el contenido de lo narrado, con el fin de que el lector pueda ubicar con facilidad información que Herrera consideró relevante (i. e. nombres de lugares, personajes, eventos notables); otras, en cambio, constituyen comentarios construidos a partir de citas textuales a autores clásicos y modernos. Aunque ambos tipos de notas tienen la capacidad de establecer un juicio valorativo sobre los eventos que acompañan (p. e. a través de una simple adjetivación), el segundo tipo de notas pretende fijar de forma más explícita una lectura o interpretación determinada de los hechos de la conquista.

Si bien en la narración de la primera conquista del Río de la Plata aparecen ambos tipos de notas, resultan más relevantes aquellas que conforman comentarios interpretativos. Los mismos se conformaron en su mayoría con citas textuales de uno de los primeros comentaristas políticos del historiador latino Cayo Cornelio Tácito (56 d. C- 120 d. C.), Annibale Scoto (m. 1589), tomados de su obra In P. Cornelii Taciti Annales, et Historias Comentarii ad politicam $\mathcal{E}$ Aulicam rationem praecipie spectantes (Roma, 1589). ${ }^{27}$ El texto de Scoto tuvo una amplia difusión europea, acompañando la importancia que la lectura del antiguo historiador tuvo para el pensamiento político europeo de fines del siglo XVI y principios del XVII (Momigliano, 1947: 95-97; Burke, 1991: 484-487). Herrera, de hecho, había traducido los Anales de Tácito (Martínez Bermejo,

\footnotetext{
${ }^{26}$ Herrera también calificó como "bárbaros"· a los guaycurúes del Chaco, en un contexto en el que también encarece la capacidad de Cabeza de Vaca para apaciguarlos (Herrera, 1615: década 7, libro 4, cap. 15, p. 104).

${ }_{27}$ Solo dos de la catorce notas-comentario referidas a la primera conquista del Río de la Plata no son citas a Scoto: la que aparece en el capítulo XVI del libro 4 de la séptima década, que contiene a una cita al humanista Justus Lipsius (1547-1606) y otra en el capítulo XV del libro 10 de la misma década que se tomó directamente de los Anales de Tácito. Dejaremos también por fuera del análisis las notas que refieren exclusivamente a los conflictos entre los conquistadores.
} 
2010: 95; Cuesta Domingo, 1998: 84), por lo que estaba profundamente familiarizado con él y con sus comentaristas más importantes.

La apelación a la tradición clásica como una forma de abordar el Nuevo Mundo se había utilizado desde sus primeras descripciones. En el caso del relato de la primera conquista rioplatense, Herrera estaba evidentemente interesado en fijar una lectura política de sus avatares, citando casi exclusivamente a Scoto en lugar de a Tácito. Esta elección se relaciona con su defensa de los justos títulos de los reyes españoles sobre la conquista de las Indias, una de las metas fundamentales de su escritura. Esto estaba alineado con una de las interpretaciones dominantes de Tácito en el período, concentrada en el problema de la conservación del poder y el establecimiento de un dominio político exitoso (Burke, 1991: 485). ${ }^{28}$ Pero además, las referencias oblicuas a la historia del mundo clásico tenían como fin "ayudar al lector a entender y recordar la secuencia y la naturaleza de los eventos: para capturar qué pasó, porqué pasó y porqué era importante" (MacCormack, 2009: 84). Así, a la vez que fijaba una interpretación política de los eventos de la conquista, Herrera auxilió a sus lectores estableciendo analogías entre ella y la historia de la expansión romana sobre Galia y Germania. Convirtiendo ambos eventos en comparables, el cronista realizó una traducción cultural, expresando y relacionado dos experiencias distintas como equivalentes, al utilizar instancias significativas de la cultura de los receptores del mensaje para que comprendieran otras más distantes en términos culturales (aunque no en el tiempo). La operación se basa en asimilar a la corona española con el imperio romano (estados organizados, expansionistas y positivamente valorados) y contraponerlos a los nativos americanos, presentados como los antiguos habitantes de Germania y Galia: bárbaros que aunque no carentes de todo mérito, eran considerados inferiores y destinados a la conquista.

Así, cuando Herrera narró que Francisco, un cacique guaraní cristianizado, auxilió a los conquistadores que subían por el río Paraná en 1542 defendiéndolos de los ataques de otros indios (Herrera, 1615, Década 7, Libro 4, cap. XVIII, p. 101), se agregó en el margen un comentario de Scoto: "Y esto lo vemos hoy en día, más claro que la luz, que la Galia cayó por sus propias fuerzas". ${ }^{29}$ El comentarista refería a un pasaje de las Historias de Tácito donde se afirma que fueron las fuerzas auxiliares de bátavos y belgas -más que las romanas- las que aplastaron una rebelión contra Nerón (Tácito, Hist., 4, 17, 6).

\footnotetext{
${ }^{28}$ Esta lectura, coexistió durante la modernidad clásica con otras que rescataba un mensaje antiimperialista (Ginzburg, 2000 [1999]: 101-102) y crítico de las monarquías europeas (Burke, 1991: 484).

29 "Et hoc hodie videmus luce clarius Galliam suismet viribus concidere" (Scotus, 1589: f. 584). Probablemente el comentario de Scoto resonaría entre sus lectores contemporáneos en relación a las Guerras de Religión que se extendieron en Francia en la segunda mitad del siglo XVI. Las traducciones del latín a la obra de Scoto pertenecen a la Lic. Mariana Franco y han sido revisadas por la Dra. Marcela Suárez, a quienes agradecemos.
} 
El paralelo que Herrera buscó trazar entre la historia antigua y la más reciente en las Indias es obvio: así como los galos habían sido derrotado por otros galos, asegurando el dominio romano, los indios amigos (en este caso, los guaraníes) auxiliarían a los conquistadores españoles para vencer a otros indios, fortaleciendo el dominio de su rey.

Si bien el texto de Herrera no es especialmente rico en descripciones etnográficas debido a la naturaleza de su proyecto historiográfico, una sección dedicada a guaraníes y agaces aparece comentada con una nota que profundiza la evaluación política que pretendía cimentar el cronista:

“Esta nación de los guaraníes se entiende por su lengua con todas las otras de las provincias del Río de la Plata, engordan a los cautivos en guerra para comerlos y los hacen grandes regalos y cuando ya está a punto, comienzan las fiestas y los bailes y de la misma manera que se dijo, que lo usan los brasiles, $^{30}$ le comen con grandes cantares y fiestas. Los agaces del río Paraguay es nación de grandes cuerpos y valientes, andan en canoas hechos corsarios por el río, ni siembran ni labran, y toda la guerra hacían a los guaraníes, para rescatar comida con los cautivos. Los castellanos tuvieron guerra con ellos y después asentaron paz, y la rompieron" (Herrera, 1615: década. 7, libro 4, cap. XIV, p. 102).

El segmento recupera la separación, firmemente establecida en los textos de los protagonistas y testigos de las primeras etapas de la conquista del Río de la Plata, entre guaraníes-cultivadores-amigos (aunque caníbales) y agacescorsarios-enemigos. Pero a través de la nota marginal que lo acompaña, se abre tanto a un juicio político sobre la conquista como una valoración ambigua de los nativos rioplatenses.

La nota, construida con una cita a Scoto indica que "Con poca dificultad son reducidos los pueblos que estuvieron acostumbrados a servir. Pero quienes siempre vivieron en libertad difícilmente son dominados. Y una vez vencidos muy difícilmente conservados bajo tutela". ${ }^{31}$ El texto de Tácito al que Scoto refería abonaba un lugar común en la literatura y la historiografía romana, el contraste entre naciones supuestamente libres como los pueblos de Occidente (los romanos republicanos primero, los galos y germanos luego) y aquellas

\footnotetext{
${ }^{30}$ Así se denominaba a las sociedades tupíes que habitaban la costa atlántica brasileña. Dado que pertenecen al mismo tronco lingüístico que los guaraníes y comparten numerosos rasgos culturales, fueron fácilmente asimilados (Silva Noelli, 2004: 22). La referencia a la comunicabilidad del guaraní permitía matizar su supuesta barbarie, ya que la existencia de una lengua franca era un rasgo positivamente valorado (Pagden, 1993: 120).

31 "Pauca cum difficultate subiguntur gentes, que servire consueverunt: sed qui semper cum libertate vixerunt, hi difficillime superantur. Et superati, in fide difficilius retinentur" (Scoto, 1589: 585).
} 
consideradas esclavas, como las que moraban en Oriente (Tácito, Hist., 4, 17, 8). Más allá de la dificultad de ponderar el juicio de Tácito sobre el estado y la valoración de la libertad entre sus pares, tanto la lectura de Scoto como aquella de Herrera se concentraban en explorar los desafíos del establecimiento de un dominio político exitoso sobre sociedades consideradas libres. Al aplicar esta lectura a la situación del Río de la Plata, guaraníes y agaces quedan bajo una serie de luces contrapuestas, no solo por los rasgos que se describen de ellos, sino también por la valoración de su atributo como "pueblos libres": el núcleo positivo implícito en la calificación es relativizado en tanto y en cuanto esa libertad era peligrosa para la instauración de un firme dominio colonial sobre ellos. La experiencia romana antigua permitió así traducir los desafíos modernos del establecimiento de un imperio transoceánico, advirtiendo sus dificultades pero insinuando sus premios: después de todo, los antiguos galos y germanos se habían convertido en los franceses y alemanes que conocía Herrera.

El resto de las notas marginales al relato de la primera conquista del Río de la Plata que nos interesa analizar se concentraron en la ponderación de distintas estrategias para lograr la sujeción de sus nativos. La figura de Cabeza de Vaca, tomada por el cronista como paradigma del buen servidor del rey, es central para explicar la forma en que deberían componerse los vínculos con aquellos, nuevamente asimilados a los bárbaros galos y germanos con los que habían luchado los romanos en la antigüedad. Comentando la acción un legado filorepublicano de Nerón que estabilizó Armenia "usando más del tacto que de la fuerza" (Tácito, Ana., 12, 49, 2), Scoto afirmó que “Los varones prudentes y experimentados componen la situación más con moderación que con fuerza". ${ }^{32}$ Herrera utilizó este comentario para indicar que Cabeza de Vaca, "varón de prudencia y experiencia, procuraba domar aquellos bárbaros por bien, antes que por las armas" (Herrera, década 7, libro 4, cap. XV, p. 104). Si bien en el cuerpo del texto de Herrera se describe que el gobernador decidió ir a una "guerra justa" contra los agaces, el énfasis puesto aquí y en otras notas ${ }^{33}$ destaca más bien el valor de la prudencia en la construcción de alianzas duraderas, incluso cuando estas debieran establecerse con los nuevos "bárbaros" del otro lado del mar.

Aunque el uso de la moderación frente a las sociedades nativas tenía por fin establecer un firme dominio sobre ellas, las colocaba al mismo tiempo como sujetos de alianza, tomando distancia de los tonos más negativos del concepto de barbarie. Al relatar la forma en que Cabeza de Vaca defendió su política de relación con los nativos, Herrera destacó que

\footnotetext{
32 "Prudentes et experientiae pleni viri, plura moderatione, quam vi componunt" (Scoto, 1589: 298). (Herrera, 1615: década 7, libro 4, cap. 15, p. 104)

${ }_{33}$ Por ejemplo, la que aparece en el folio 160 del cap. XIV, libro 7 de la séptima década.
} 
"no placía mucho a su gente porque al soldado siempre es la paz aborrecible; pero el gobernador decía que con los pacíficos $\mathrm{y}$ amigos eran respetados de las otras naciones; porque si todos eran enemigos era imposible ir penetrando por aquellas tierras ni conservarlas y que por tanto convenía aprovecharse de la astucia, no mostrando franquezas" (Herrera, década 7, libro 7, cap. XVI, p. 163). ${ }^{34}$

Acompañando esta sección, que resalta tanto la posibilidad alianza con los nativos como las diferencias entre los conquistadores, Herrera volvió a citar a Scoto. El texto referido de Tácito relataba cómo dos caudillos germanos, restablecieron la paz con los romanos después de algunas turbulencias (Tácito, Ana., 1, 57, 2). La enseñanza política que extrajo Scoto se concentró en la potencialidad ordenadora de los tratos pacíficos, aunque más no sea con el fin de evitar mayores peligros a los nuevos amos:

"Pues con la ayuda de ellos y la notoriedad de nuestra clemencia, retendremos en el deber a todas las provincias que, de no ser así, irritadas por la violencia y la crueldad podrían separarse de nosotros $\mathrm{y}$, al mismo tiempo, uniéndose con nuestros enemigos ocasionar un enorme peligro para nosotros." 35

Herrera destacó en esta lectura la prudencia estratégica del divide et impera, y su combinación necesaria con la construcción de alianzas y la astucia. Esta perspectiva aparece como atributo de los buenos servidores reales, quienes entendían que la posibilidad de mantener y ampliar las conquistas en las Indias era una función del uso estratégico de la paz y las alianzas, tal y como el ejemplo de la "clemencia romana" había permitido ganar Germania.

No obstante las preferencias declaradas Herrera, la conquista del Río de la Plata no fue llevada adelante por el supuestamente prudente Cabeza de Vaca, expulsado de la gobernación por sus primeros conquistadores en 1545. El relato del final de esta primera etapa de la conquista rioplatense quedó así marcado por la traición a las órdenes reales, el maltrato consecuente a sus nativos y la falta de castigo a quienes habían depuesto al legítimo representante del monarca. Sin embargo, tal y como Herrera podía constatar, la conquista del Río de la Plata había resistido, y aunque sin arrojar los premios de México o Perú, mantuvo el dominio de los reyes españoles sobre un sector más de las Indias.

\footnotetext{
${ }^{34}$ Este comentario se refiere a las relaciones que Cabeza de Vaca quería establecer con los nativos del puerto de Reyes, situado en el curso superior del Paraguay.

35 “Nam eorum ope, et clementiae nostrae fama, retinebimus in officio provincias totas, qua alioquin, vi et saevitia irritatae, a nobis desciscere possent, et una cum hostibus nostris se coniungendo, periculum ingens nobis facescere (sic)." (Scoto, 1589: 52).
} 
En definitiva, tal y como la Galia había caído por sus propias fuerzas, también lo había hecho el distante Paraguay, aunque si deparar un botín comparable.

\section{Conclusiones: traducciones entre experiencias, testimonios e historiografía}

Este trabajo se propuso analizar dos instancias de producción y circulación de representaciones sobre los nativos del Río de la Plata. Primero, se consideraron aquellas tributarias de experiencias directas sobre el terreno; luego las que se conformaron en la Historia general de los hechos de los castellanos, del cronista real Antonio de Herrera y Tordesillas. Tomar ambas como casos de traducción cultural nos permitió considerar, de forma general, las distintas operaciones que fueron necesarias para hacer comprensibles y difundir información $\mathrm{y}$ representaciones sobre América en la modernidad clásica. La traducción cultural permitió establecer paralelos entre las ideas etnográficas arraigadas en la tradición etnográfica europea y las experiencias novedosas atestiguadas en el Nuevo Mundo, produciendo los entendimientos necesarios para asegurar, por lo menos, una comprensión operativa de ellas. Esos equivalentes, por precarios e inexactos que fueran, constituyeron las bases de un conocimiento dinámico que acompañó el desarrollo del dominio colonial y permitió una dramática ampliación de las ideas etnográficas de los europeos, que ya no podrían limitarse a las tradiciones locales del Viejo Mundo. Para que ello fuera posible, fue necesario realizar operaciones capaces de mediar entre las tradiciones y las novedades, encontrando equivalentes más o menos precarios que permitieran expresar la diferencia cultural en términos comprensibles para sus testigos y receptores a la distancia.

Eran así necesarias, traducciones culturales de distinto tipo. El concentrarnos en las representaciones producidas a propósito de guaraníes y agaces en la instancia inicial de la conquista del Río de la Plata y su proyección en la obra de Herrera, hizo posible reconstruir tanto una genealogía de sus representaciones como el repertorio de las herramientas conceptuales y eruditas utilizadas para hacerlos aprehensibles. Las importantes diferencias contextuales que caracterizaron a ambos registros se expresaron en distintas estrategias de traducción de los nativos rioplatenses. Así, pudimos establecer que en el registro de los testigos directos de los nativos rioplatenses resultaron cruciales las valoraciones relacionadas con el mantenimiento de la conquista y la posibilidad de realizar alianzas, traducidas a través del lenguaje de la producción agrícola y la piratería, según se tratara de guaraníes o agaces respectivamente. Al mismo tiempo, surgía una visión más acotada y circunscripta de las prácticas antropofágicas de los primeros, lejos de las representaciones que habían caracterizado sus descripciones inaugurales. A su vez, las tradiciones etnográficas europeas y algunas referencias vinculadas a instancias previas de la conquista de América (como lo es la referencia a los 
caribes), constituyeron el sustrato de traducción que permitió explicar sus características a las autoridades españolas.

Luego, pudimos rastrear cómo este sustrato testimonial se reubicó en el registro historiográfico-oficial de Herrera. Como en otras partes de su Historia general, el cronista reprodujo en gran medida las categorías que halló en sus fuentes. Pero considerando la naturaleza historiográfica de la obra, su fin político y el público español y europeo al que iba dirigida, Herrera se apartó de ellas tanto para reforzar su argumento sobre los justos títulos de la corona española, como para facilitar a sus lectores la comprensión de lo relatado. Su traducción de las representaciones de guaraníes y agaces se construyó a través del uso de la categoría de barbarie y de las intervenciones realizadas a través del comentario político de la obra de Tácito en las notas marginales. Ambas estrategias fueron fundamentales para traducir a sus nuevos públicos los ya remotos eventos de la conquista rioplatense, encontrando nuevos términos comunes que los volvieran comprensibles. Los préstamos, deslizamientos y reacomodamientos necesarios en ambas instancias para traducir a los nativos del Río de la Plata fueron todas operaciones que, aunque diversas en sus medios y estrategias, construyeron los lazos representacionales que transformaron las riberas del extraño río sin orillas en un dominio, lejano pero asible, del rey español.

Ciudad de Buenos Aires, abril de 2020

\section{Bibliografía}

Adorno, Rolena; Pautz, Paul Charles (1999). Alvar Núñez Cabeza de Vaca. Volume 3, University of Nebraska Press: Lincoln y Londres.

Asad, Talal (1986). "The concept of cultural translation in British social anthropology", en Clifford, James; Marcus George E. (eds.) Writing culture. The poetics and politics of ethnography, Berkeley: University of California Press, pp. 141-164.

Bauer, Ralph (2003). The cultural geography of colonial American literatures. Empire, travel, modernity, Cambridge: Cambridge University Press.

Brendecke, Arndt (2016 [2012]). Imperio e información. Funciones del saber en el dominio colonial español, Madrid y Frankfurt: Iberoamericana-Vervuet.

Burke, Peter (1991). “Tacitism, scepticism, and reason of state”, en Burns, J. H. (ed.) The Cambridge History of Political Thought, 1450-1700, Cambridge: Cambridge University Press, pp. 479-498.

Burke, Peter (2007). "Cultures of translation in Early Modern Europe", en Burke, Peter y Po-chi Hsia, Ronnie (eds.) Cultural translation in Early Modern Europe, Cambridge: Cambridge University Press, pp. 7-38. 
Burke, Peter (2009). Cultural hibridity, Cambridge: Polity.

Carneiro Da Cunha, Manuela L.; Viveiros de Castro, Eduardo B. (1985). "Vingança e temporalidade: os tupinamba", en JSA, vol. LXXI, pp. 191-208.

Carvalho, Silvia, M. Schmuziger (1992). "Chaco: encruzilhada de povos e 'melting pot' cultural, suas relações com a bacia da Paraná e o sul matogrossense", en Carneiro Da Cunha, Manuela L. (org.) História dos índios no Brasil, San Pablo: Companhia das Letras, 457-474.

Chartier Roger (1991). El mundo como representación. Estudios sobre historia cultural. Barcelona: Gedisa.

Chartier, Roger (2016 [2015]). La mano del autor y el espíritu del impresor. Siglos XVI-XVIII, Buenos Aires: Katz.

Covarrubias, Sebastián (1611). Tesoro de la lengua castellana o española, Madrid: Luis Sánchez, impresor del Rey.

Cuesta Domingo, Mariano (1998). Antonio de Herrera y su obra, Segovia: Colegio Universitario de Segovia.

Cuesta Domingo, Mariano (2007). “Los cronistas oficiales de Indias. De López de Velasco a Céspedes del Castillo", en Revista Complutense de Historia de América, vol. 33, pp. 115-150.

El Jaber, Loreley (2012). “Álvar Núñez Cabeza de Vaca. Gustos y olvidos. Legalidad, viaje y escritura", en Cuadernos del CILHA, vol. 13, núm. 17, 2012, pp. 56-73.

Gandini, María Juliana (2012). Experiencias desde los márgenes. Armas, letras y alteridad en los Comentarios de Álvar Núñez Cabeza de Vaca", en Anuario del Centro de Estudios Históricos "Prof. Carlos S. A. Segreti", año 12, núm. 12, pp. 8196.

Gandini, María Juliana (2013). “Traduciendo a los otros: cadenas de interpretación entre América y Europa en torno a los Naufragios de Álvar Núñez Cabeza de Vaca", en Gandini, María Juliana; López Palmero, Malena; Martínez Carolina; Paredes, Rogelio C., Fragmentos Imperiales. Textos e imágenes de los imperios coloniales en América. Siglos XVI-XVIII, Buenos Aires: Biblos, pp. 23-45.

Gandini, María Juliana (2019). “Bárbaros en la frontera norte del Nuevo Mundo. Los usos de la tradición clásica en la representación de los nativos de la Florida entre testimonios directos y recepciones europeas (1528-1615)", en Eadem Utraque Europa, año 15, núm. 20, pp. 23-62.

Genette, Gérard (1989 [1962]). Palimpsestos. La literatura en segundo grado, Madrid: Taurus.

Ginzburg, Carlo (2000 [1999]). Rapporti di forza. Storia, rethorica, prova, Milán: Feltrinelli. 
Ginzburg, Carlo (2010 [2006]). El hilo y las huellas. Los verdadero, lo falso, lo ficticio, Buenos Aires: FCE.

Ginzburg, Carlo (2011 [1998]). Occiacci di legno. Nove reflessioni sulla distanza, Milán: Feltrinelli, pp. 136-170.

Guérin, Miguel Alberto (2000). "La organización inicial del espacio rioplatense", en Tandeter, Enrique (dir.) Nueva Historia Argentina. La Sociedad Colonial, Buenos Aires: Sudamericana, pp. 13-54.

Hanks, William F. (2015). "The space of translation", en Hanks, William F.; Severi, Carlo (eds.) Translating worlds..., ob. cit., pp. 21-49.

Hanks, William F. y Severi, Carlo (2015). "Introduction”, en Hanks, William F.; Severi, Carlo (eds.) Translating worlds. The epistemological space of translation, Chicago: Hau Books, pp. 1-20.

Hartog, François (2003 [1980]). El espejo de Heródoto, Buenos Aires: FCE.

Herrera y Todesillas, Antonio de (1615). Historia general de los hechos de los castellanos... Madrid: Por Juan de la Cuesta.

Herrera y Tordesillas, Antonio de (1601). Historia general de los hechos de los castellanos... Madrid: Por Juan Flamenco.

Jakobson, Roman (1959). “On linguistic aspects of translation", en On translation, núm. 3, pp. 232-239.

Kagan, Richard (2009). Clio and the Crown. The Politics of History in Medieval and Early Modern Spain, Baltimore: The John Hopkipns Universiry Press.

Kohut, Karl (2010). “Las primeras crónicas de Indias y la teoría historiográfica”, en Colonial Latin American Review, 18, pp. 153-187.

Kwiatkowski, Nicolás (2017). "Palabra e imagen en la modernidad temprana. Representaciones de la barbarie mediante ilustración, écfrasis y alegoría”, en Boletín de estética, año XIII, núm. 39, pp. 43-94.

Kwiatkowski, Nicolás (2020). "Fuimos muy peores en vicios y costumbres brutales". Barbarie, propia y ajena, entre la caída de Constantinopla y la Ilustración, Buenos Aires: Eudeba.

Leavitt, John (2015). "Words and worlds. Ethnography and theories of translation", en Hanks, William F. y Severi Carlo (eds.) Translating worlds... ob. cit., pp. 259-293.

Lestringant, Frank (1997 [1994]). The discovery and representation of the cannibal from Columbus to Jules Verne, Berkeley: University of California Press.

López de Mariscal, Blanca (2004). Relatos y relaciones de viaje al Nuevo Mundo en el siglo XVI: un acercamiento a la identificación del género, Madrid: PolifemoTecnológico de Monterrey. 
MacCormanck, Sabine (2009). In the wings of time. Rome, the Incans, Spain and Perú, Princeton y Oxford: Princeton University Press.

Marin, Louis (1988). "Le cadre de la représentation et quelques-unes de ses figures", en Les Cahiers de Musée National d'Art Moderne, núm. 24, pp. 62-81.

Martínez Bermejo, Saúl (2010). Translating Tacitus: the reception of Tacitus's works in the vernacular languages of Europe, 16th-17th centuries, Pisa: Plus Ultra University Press.

Melià, Bartomeu (1999). "Sociedades fluviales y selvícolas del este: Paraguay y Paraná", en Rojas Rabiela, Teresa; Murra, John (dirs.) Historia general de América Latina. Volumen I, París: Editorial Trotta-UNESCO, pp. 335-552.

Mignolo, Walter (1980). “Cartas, crónicas y relaciones del descubrimiento y la conquista", en Madrigal, Íñigo L. (dir.) Historia de la Literatura Hispanoamericana. Época Colonial, Madrid, Cátedra, 1980, pp. 57-116.

Momigliano, Arnaldo (1947). "The first political commentary on Tacitus", en The Journal of Roman Studies, vol. 37, parte 1 y 2, pp. 91-101.

Núñez Cabeza de Vaca (1555). Comentarios de Alvar Nuñez Cabeça de Vaca...,Valladolid: Francisco Fernandez de Cordoua.

Pagden, Anthony (1986 [1982]). The fall of natural man. The American Indian and the origins of comparative ethnology, Cambridge: Cambridge University Press.

Pagden, Anthony (1993). European encounters with the New World. From Renaissance to Romanticism, New Haven: Yale University Press.

Ricoeur, Paul (2009 [2004]). Sobre la traducción, Buenos Aires: Paidós.

Roulet, Florencia (1993). La resistencia de los guaraní del Paraguay a la conquista española (1537-1556), Posadas: Editorial Universitaria de la Universidad Nacional de Misiones.

Rowe, John H. (1964). "Ethnography and ethnology in the Sixteenth Century", en Kroeber Anthropological Society Papers, vol. 30, pp. 1-19.

Schmidel, Ulrich (1903 [1557]). Viaje al Río de la Plata (1534-1554), Buenos Aires: Cabaut y Cía. Editores.

Schwartz, Stuart B. (1994). "Introduction", en Implicit understandings. Observing, reporting, and reflecting on the encounters between European and other peoples in the Early Modern Era, Nueva York: Cambridge University Press, pp. 1-19.

Scoti Placentini, Annibalis (1589). In P. Cornelii Taciti Annales, et Historias Comentarii ad politicam..., Roma: Apud Bartholomaeum Grassium.

Silva Noelli, Francisco (2004). "La distribución geográfica de las evidencias arqueológicas guaraní", en Revista de Indias, vol. LXIV, núm. 30, pp. 17-34. 
Steiner, George (1980 [1975]). Después de Babel. Aspectos del lenguaje y la traducción, México: FCE.

Susnik, Branislava (1965). El indio colonial del Paraguay. El guaraní colonial, Asunción: Museo Etnográfico "Andrés Barbero".

Susnik, Branislava (1982). El rol de los indígenas en la formación y en la vivencia del Paraguay. Tomo I, Asunción: Universo.

Susnik, Branislava (1983). El rol de los indígenas en la formación y en la vivencia del Paraguay. Tomo II, Asunción: Universo.

Tácito, Cornelio (1979). Anales. Libros I-IV, Barcelona: Gredos.

Tácito, Cornelio (1980). Anales. Libros XI-XVI, Barcelona: Gredos.

Tácito, Cornelio (2013). Historias. Libros III-V. Barcelona: Gredos.

White, Richard (1991 [2011]). The middle ground. Indians, empires, and republics in the Great Lakes region, 1650-1815, Cambridge: Cambridge University Press. 